\title{
Extracellular RNAs from lung cancer cells activate epithelial cells and induce neutrophil extracellular traps
}

\author{
YAN LI $^{*}{ }^{*}$, YONGLIN YANG $^{2,3^{*}}$, TINGTING GAN ${ }^{1}$, JIAWEI ZHOU $^{1}$, FAN HU $^{4}$, NANNAN HAO ${ }^{3}$, \\ BAORUI YUAN ${ }^{3}$, YU CHEN $^{1}$ and MINGSHUN ZHANG ${ }^{3,5}$ \\ ${ }^{1}$ Department of Anesthesiology, First Affiliated Hospital of Nanjing Medical University, Nanjing, Jiangsu 210029; \\ ${ }^{2}$ Department of Infectious Disease, Nanjing Medical University Nanjing First Hospital, Nanjing, Jiangsu 210006; \\ ${ }^{3}$ Key Laboratory of Antibody Technique of Health Ministry, ${ }^{4}$ State Key Laboratory of Reproductive Medicine, \\ ${ }^{5}$ Department of Immunology, Nanjing Medical University, Nanjing, Jiangsu 210016, P.R. China
}

Received August 13, 2018; Accepted May 13, 2019

DOI: $10.3892 /$ ijo.2019.4808

\begin{abstract}
Neutrophil infiltration is frequently observed in lung cancer tissues. Extracellular RNAs (exRNAs) may facilitate tumor progression. The present study investigated the cross-talk of tumor exRNAs and neutrophil extracellular traps (NETs) in lung cancer. Lewis lung carcinoma (LLC) cells were cultured with the deprived sera. And the cell culture supernatants (CCS) were analyzed in vitro and in vivo. The results revealed that exRNAs from lung cancer CCS promoted the inflammatory cytokine interleukin- $1 \beta$ and reduced the vascular cell adhesion molecule-1 expression in lung epithelial cells. Lung cancer CCS-treated epithelial cells induced the production of NETs. By contrast, NETs reduced the tight junction protein claudin-5 in epithelial cells. Furthermore, NETs caused the necrosis of epithelial cells, which resulted in the release of exRNAs. In mice, lung cancer cells instilled in the lung recruited neutrophils and initiated NETs. In patients with lung cancer, NETs were also observed. These results suggested that exRNAs in the cell culture supernatant may indirectly induce NETs and contribute to lung cancer oncogenesis.
\end{abstract}

Correspondence to: Dr Yu Chen, Department of Anesthesiology, First Affiliated Hospital of Nanjing Medical University, 300 Guangzhou Road, Nanjing, Jiangsu 210029, P.R. China

E-mail: yuchen_njmu@163.com

Dr Mingshun Zhang, Key Laboratory of Antibody Technique of Health Ministry, Nanjing Medical University, and Department of Immunology, Nanjing Medical University, 818 Tianyuan Road, Nanjing, Jiangsu 210016, P.R. China

E-mail: mingshunzhang@njmu.edu.cn

*Contributed equally

Key words: extracellular RNAs, neutrophil extracellular traps, lung cancer, epithelial cells, interleukin-1 $\beta$

\section{Introduction}

Lung cancer is the leading cause of cancer-related mortality (1). As the first line of immune defense, neutrophils fight against infectious agents via phagocytosis, degranulation (2) and neutrophil extracellular traps (NETs) (3). NETs, were firstly identified as an immune defense mechanism against bacteria (3), have been well documented in a diverse range of diseases (4-6). In response to various stimuli, neutrophils release extracellular chromatins coupled with granular and selected cytoplasmic proteins. In patients with lung cancer, elevated number of circulating neutrophils are a potential biomarker of poor prognosis (7). In systemic sepsis, intravascular neutrophils produce NETs, which sequester the circulating lung tumor cells (8). Although infection in patients with lung cancer is concomitant (9), systemic sepsis is not inevitable. In aseptic inflammation, whether neutrophils that have infiltrated the parenchyma of patients with lung cancer can form NETs, is unknown.

In the central dogma of biology, RNA function is cell autonomous (10). With the aid of ribosomal RNA and transfer RNA, messenger RNA transcribed from the genome is translated into protein in the cell. Previous studies have demonstrated the transfer of macromolecular RNA between mammalian cells $(11,12)$ may trigger a broad range of physiologic and pathologic processes. Compared with non-tumor cells, tumor cells secrete higher levels of exRNAs (13). Therefore, in the sera of patients with lung cancer the concentration of extracellular RNA (exRNA) $s$ is significantly elevated (14). The profile of microRNAs (miRNAs), the major population of exRNAs, is considered as a diagnostic marker and therapeutic candidate for lung cancer (15-17). Besides miRNAs, extracellular mRNAs may also be functional. For example, Gag-encoding mRNA has the potential to promote the secretion of tumor necrosis factor- $\alpha$ (TNF- $\alpha$ ) and activate dendritic cells (18). In the myocardial ischaemia reperfusion injury, RNase1 has been demonstrated to be protective via degrading mRNAs (19). RNasel/exRNA balance is also linked with tumor invasion (13). However, the cross-talk between lung cancer exRNAs and neutrophils still remains unknown. 
The aim of the present study was to investigate the roles of exRNA in the formation of NETs in a mouse model of lung cancer and in patients with lung cancer. Furthermore, the contribution of NETs to the activation and damage of epithelial cells was investigated. Collectively, the present findings indicated that the cross-talk between exRNAs from lung cancer cells and NETs may contribute to the oncogenesis of lung cancer which may shed light on a new strategy for treating lung cancer.

\section{Materials and methods}

Animals. A total of 80 wild-type female C57BL/6 mice, aged 6-8 weeks old, weighing 25-33 g were purchased from the College of Veterinary Medicine, Yangzhou University (Yangzhou, China) and bred in the Animal Laboratory of Nanjing Medical University (Nanjing, China), under standard laboratory conditions $(12: 12 \mathrm{~h}$ light: dark cycle, relative humidity $60 \pm 5 \%$, temperature $25 \pm 2{ }^{\circ} \mathrm{C}$ ) in individually ventilated cages with free access to water or food. All animal procedures were approved by the Institutional Animal Care Committee of Nanjing Medical University.

Cell culture. The murine lung cancer cell line Lewis lung carcinoma (LLC) was acquired from the Cell Bank of Shanghai Institutes for Biological Sciences (Shanghai, China). And the catalog number for LLC was TCM 7 (www.cellbank. org.cn/detail_1.asp?id=78\&serial=TCM\%207). The Murine Lung Epithelial-12 (MLE-12) cell line was obtained from the American Type Culture Collection. The LLC and MLE-12 cells were maintained in high-glucose Dulbecco's modified Eagle's medium (DMEM; HyClone; GE Healthcare Life Sciences) with $10 \%$ fetal bovine serum (FBS; Gibco; Thermo Fisher Scientific, Inc.) in a $5 \% \mathrm{CO}_{2}$ humidified atmosphere at $37^{\circ} \mathrm{C}$.

Protocol of harvesting exRNAs. exRNAs were prepared as previously described by Laurent and Alexander (20). Briefly, LLC or MLE-12 cells were seeded in $25-\mathrm{cm}^{2}$ cell culture flasks. Once the cells had covered $75 \%$ of the flask, the culture medium was removed and the flask was washed gently with pre-warmed PBS. The PBS was then discarded and $2 \mathrm{ml}$ low-glucose DMEM (HyClone; GE Healthcare Life Sciences) without FBS was added to the flask for $48 \mathrm{~h}$ at $37^{\circ} \mathrm{C}$. After centrifugation at $2,000 \mathrm{x} \mathrm{g}$ for $10 \mathrm{~min}$ at $4{ }^{\circ} \mathrm{C}$, the supernatant (cell culture supernatant; CCS) was collected and stored at $-80^{\circ} \mathrm{C}$. A total of 20 and $50 \%$ CCS in the culture medium significantly increased IL-1 $\beta$ transcription (data not shown). Therefore, 50\% CCS was selected for the subsequent experiments. To validate whether the CCS contained exRNAs, it was treated with RNase1 $(0.5 \mu \mathrm{g} / \mu \mathrm{l}$; cat. no. R4875; Sigma-Aldrich; Merck KGaA) and then subjected to electrophoresis on a $3 \%$ agarose gel. The results were analyzed in a Tanon system (Tanon 4600SF; Tanon Science and Technology Co., Ltd.) at $310 \mathrm{~nm} \mathrm{UV.}$

The RNA in the LLC cells prior to and following starvation was also directly stained with $\mathrm{SYTO}^{\circledR}{ }^{\circledR}$ RASelect $^{\mathrm{TM}}$ Green Fluorescent Cell Stain (cat. no. S32703; Molecular Probes; Thermo Fisher Scientific, Inc.). Briefly, the LLC cells were seeded onto cell slides and starved for $24 \mathrm{~h}$ at $37^{\circ} \mathrm{C}$.
Subsequently, the cells on the slides were washed gently with pre-warmed PBS and stained with RNA-selective dye (same as above; $500 \mathrm{nM}$ ) and DAPI for $20 \mathrm{~min}$ at room temperature. The stained cells were observed under a confocal microscope (magnification, x200).

Activation of MLE-12 cells with exRNAs. To determine whether the CCS could activate MLE-12 cells (cultured for $12 \mathrm{~h}$ at $1 \times 10^{6} / \mathrm{ml}$ cells), different concentrations of the CCS (10, 20 and $50 \%$ ) were added to the culture medium of the MLE-12 cells for $12 \mathrm{~h}$ at $37^{\circ} \mathrm{C}$. The MLE-12 cells were washed in PBS for 5 times and then collected for quantitative PCR or western blot analyses. To validate the roles of exRNAs in the activation of MLE-12 cells, CCS with or without RNase1 $(0.5 \mu \mathrm{g} / \mu \mathrm{l})$ was added to the cell culture.

Induction of NETs. Bone marrow cells were collected from the two hind leg femurs of 8-10 week-old mice $(n=15)$, were suspended in PBS, and centrifuged at $450 \mathrm{x}$ g for $10 \mathrm{~min}$ at $4^{\circ} \mathrm{C}$. The red blood cells were lysed with ACK Lysing Buffer (cat. no. A1049201; Thermo Fisher Scientific, Inc.). Briefly, prepare a lysing solution by adding $0.5 \mathrm{ml}$ of lysing buffer to $4.5 \mathrm{ml}$ of sterile water and lyse the remaining red blood cells with $5 \mathrm{ml}$ of lysing solution. Lysing solution was transferred into centrifuged tube contains pellets on ice in the dark for $10 \mathrm{~min}$ (21). The cells were then subjected to a discontinuous 72-64\% Percoll ${ }^{\circledR}$ (cat. no. P4937; Sigma-Aldrich; Merck KGaA) density gradient centrifugation at $450 \mathrm{x} \mathrm{g}$ for $30 \mathrm{~min}$ at $4^{\circ} \mathrm{C}$. The neutrophils were collected at the $72-64 \%$ Percoll $^{\circledR}$ interface and washed three times with PBS at $4^{\circ} \mathrm{C}$. The neutrophils $\left(5 \times 10^{6}\right.$ cells) were seeded in $10-\mathrm{cm}$ culture plates that were pre-treated with attachment factor protein (cat. no. S006100; Gibco; Thermo Fisher Scientific, Inc.). To mimic the roles of exRNAs, the cells were stimulated with $10 \mu \mathrm{g} / \mathrm{ml}$ poly(I:C; InvivoGen) at $37^{\circ} \mathrm{C}$ for $4 \mathrm{~h}$ (21). The supernatant was removed slowly and the plate was gently washed with pre-warmed PBS. The plate was then flushed with $1 \mathrm{ml} \mathrm{PBS}$ at $4^{\circ} \mathrm{C}$ for 5 times to separate the NETs from the bottom of the plate. After centrifugation at $450 \mathrm{x}$ g for $10 \mathrm{~min}$ at $4^{\circ} \mathrm{C}$, the supernatant containing the NETs was transferred to $1.5 \mathrm{ml}$ Eppendorf tubes. The supernatant containing the NETs was further centrifuged at $18,000 \mathrm{x} \mathrm{g}$ for $10 \mathrm{~min}$ at $4^{\circ} \mathrm{C}$. The sediment (NETs) with $100 \mu 1$ residue was collected and stored at $-80^{\circ} \mathrm{C}$.

NET induction by activated MLE-12 cells. MLE-12 cells were seeded on the sterile slides of a 6 -well plate. When the cells covered $75 \%$ of the plates, CCS was added to replenish the medium and activate the MLE-12 cells. RNase1 $(0.5 \mu \mathrm{g} / \mu \mathrm{l})$ or interleukin (IL)-1 $\beta$ inhibitor AS101 $(2.5 \mu \mathrm{g} / \mathrm{ml}$; cat. no. S8301; Selleck Chemicals) was added to the CCS to block the potential roles of exRNAs or IL-1 $\beta$. After incubation for $12 \mathrm{~h}$ at $37^{\circ} \mathrm{C}$, the MLE- 12 cells were gently washed for 5 times with pre-warmed PBS. Neutrophils were added to each well for the induction of NETs. After $4 \mathrm{~h}$, the supernatant was collected for quantitative analysis. The cell slides were gently washed in $4^{\circ} \mathrm{C}$ PBS, fixed in $4^{\circ} \mathrm{C}$ acetone for $10 \mathrm{~min}$ and stained with DAPI at room temperature for half an hour in the dark.

MLE-12 cells treated with NETs. MLE-12 cells were seeded in a 6-well plate. The confluent MLE-12 cells were treated with 
NETs of 10, 20 and $50 \%$ concentration for $4 \mathrm{~h}$ at $37^{\circ} \mathrm{C}$. After the incubation, the MLE-12 cells were washed with PBS for 5 times. A number of the MLE-12 cells were harvested for western blot analysis of the tight junction protein claudin-5 and the apoptotic protein caspase 3. The remaining MLE-12 cells were seeded in a glass-bottomed dish. The NET-treated MLE-12 cells were stained with the dye propidium iodide (PI; P1304MP; Invitrogen; Thermo Fisher Scientific, Inc.) at room temperature in the dark for $10 \mathrm{~min}$ in order to identify the cell death. exRNAs from NET-damaged MLE-12 cells were quantified using the Quant-iT ${ }^{\mathrm{TM}}$ RiboGreen $^{\mathrm{TM}}$ RNA Assay Kit (cat. no. R11490; Thermo Fisher Scientific, Inc.) according to the manufacturer's protocol. The confluent living MLE-12 cells in the glass-bottomed dish were stained with $1 \mu \mathrm{m}$ CellTrace $^{\mathrm{TM}}$ Far Red DDAO-SE (C34553; Invitrogen; Thermo Fisher Scientific, Inc.) at room temperature in the dark for 15 min. The poly(I:C)-induced NETs were stained with $1 \mu \mathrm{m}$ SYTOX Green (cat. no. s7020; Invitrogen; Thermo Fisher Scientific, Inc.) at room temperature in the dark for $20 \mathrm{~min}$. The interactions between the MLE-12 cells and NETs were directly observed under a confocal microscope (magnification, x 200).

Reverse transcription-quantitative PCR. The total RNA was extracted from the MLE-12 cells using the Takara universal total RNA extraction kit (Takara Biotechnology Co., Ltd.) and cDNA was synthesized using PrimeScript RT Master Mix (Takara Biotechnology Co.,Ltd.) according to the manufacturer's protocol. Quantitative PCR was performed using SYBR-Green Universal PCR Master mix (Takara Biotechnology Co., Ltd.). The RNA expression was quantified using a StepOnePlus Real-Time PCR System (Applied Biosystems; Thermo Fisher Scientific, Inc.) under the following conditions: Denaturation for $30 \mathrm{sec}$ at $95^{\circ} \mathrm{C}$, followed by 40 cycles of denaturation for $3 \mathrm{sec}$ at $95^{\circ} \mathrm{C}$, and extension for $30 \mathrm{sec}$ at $60^{\circ} \mathrm{C}$. Melting curve analysis was performed at the end to validate the specificity of the expected PCR product. The relative expression levels of each mRNA were calculated using standard curve method (22). Three independent samples were prepared for each assay, and each experiment was performed at least three times. The primer sequences were designed using PrimerBank (pga.mgh.harvard. edu/primerbank), a public resource for PCR primers, and were as follows: IL-1 $\beta$ forward, 5'-AGCTCTCCACCTCAATGGA-3' and reverse, 5'-TTGCTTGGGATCCACACTCT-3'; IL-6 forward, 5'-GACTGATGCTGGTGACAACC-3' and reverse, 5'-AGACAGGTCTGTTGGGAGTG-3'; TNF- $\alpha$ forward, 5'-GGTGAGGCAGCAAGAGATTG-3' and reverse, 5'-GAG CAGCAGGTTTCAGGATG-3'; vascular cell adhesion molecule (VCAM)-1 forward, 5'-TTGGGAGCTGAACACTTTTCC CAG-3' and reverse, 5'-TGTGGTGCTGCAAGTCAGGAGC-3'; and GAPDH forward 5'-AACTTTGGCATTGTGGAAGG-3' and reverse, 5'-GGATGCAGGGATGATGTTCT-3'.

Western blotting. Total protein from the MLE-12 cells was isolated using radioimmunoprecipitation lysis buffer with protease and phosphatase inhibitor cocktail (Beyotime Institute of Biotechnology). The proteins were separated in a 10 or $15 \%$ SDS-polyacrylamide gel and transferred to a polyvinylidene fluoride membrane. The membranes were blocked for $1 \mathrm{~h}$ with 5\% bovine serum albumin (A1933; Sigma-Aldrich;
Merck KGaA) in PBS and then were incubated with anti-VCAM1 (cat. no. ab134047), anti-claudin 5 (cat. no. ab15106) (both from Abcam) and anti-caspase-3 (cat. no. 9665) at a 1:1,000 dilution or with anti- $\beta$-actin (cat. no. 4970) (both from Cell Signaling Technology, Inc.) at a 1:2,000 dilution overnight at $4^{\circ} \mathrm{C}$. After washing for 5 times with PBS with Tween-20, the membranes were incubated with a horseradish-conjugated anti-rabbit IgG antibody (65-6120; Invitrogen; Thermo Fisher Scientific, Inc.) at a 1:2,000 dilution for $1 \mathrm{~h}$ at room temperature. The blots were washed a further 5 times with PBS and then incubated with enhanced chemiluminescence substrate (cat. no. 35055; Thermo Fisher Scientific, Inc.) with gentle agitation for $1 \mathrm{~min}$ at room temperature. The individual target proteins were visualized and recorded using a G:BOX instrument (GENESys V1.3.5.0; Syngene).

ELISA. The concentration of IL-1 $\beta$ in the cell culture supernatant was determined via ELISA (cat. no. BMS6002; eBioscience; Thermo Fisher Scientific, Inc.) according to the manufacturer's protocol.

LLC cell-recruited and-activated neutrophils in vivo. Mice were anesthetized with a mixture of ketamine $(100 \mathrm{mg} / \mathrm{kg})$ and xylazine $(10 \mathrm{mg} / \mathrm{kg})$ via intraperitoneal injection. After exposure of the trachea, $1 \times 10^{6}$ LLC cells were injected into the lungs through a trimmed sterile 31-gauge needle inserted into the tracheal lumen. After $4 \mathrm{~h}$, the bronchoalveolar lavage fluid (BALF) and lung tissues were collected from each mouse. The bronchial and alveolar spaces were washed three times with $1 \mathrm{ml}$ PBS. The BALF from the two lungs per mouse was pooled and centrifuged at $1,000 \mathrm{x}$ g for $5 \mathrm{~min}$ at $4^{\circ} \mathrm{C}$. A total of $400 \mu \mathrm{l}$ supernatant was transferred to a new Eppendorf tube and the quantity of NETs was tested. The rest of the fluid was re-suspended for flow cytometry. After the BALF was obtained, PBS was pumped into the right ventricle to clear blood in the pulmonary vasculature. The lung tissues from one mouse were divided into three parts. The upper right lung lobe was removed and fixed in $10 \%$ neutral-buffered formalin for histopathology imaging. The left lung lobe was removed and immobilized with OCT (Sakura Finetek Europe B.V.) at $-80^{\circ} \mathrm{C}$ for $\geq 24 \mathrm{~h}$ for fluorescence microscopy. The lower right lung lobe was pulverized in $70-\mu \mathrm{m}$ cell strainers and washed with 1.0 ml PBS. ACK lysis buffer (A1049201; Gibco; Thermo Fisher Scientific, Inc.) was added to the suspension to lyse the erythrocytes. After the lysis of the erythrocytes, the cell suspension was centrifuged $700 \mathrm{x}$ g for $10 \mathrm{~min}$ at room temperature. After the centrifugation, cell pellets rom the lung homogenates were re-suspended in PBS and stained for flow cytometry.

Flow cytometry. The leukocytes from the BALF or pulverized lung were labeled with fluorescent antibodies in order to quantify the neutrophils. Briefly, the cells were first incubated with anti-CD16/32 (cat. no. 14-0161-82; Invitrogen; Thermo Fisher Scientific, Inc.; 1:60 in PBS) to reduce the non-specific binding. Subsequently, anti-CD45 conjugated with FITC (cat. no. 11-0451-82; Invitrogen; Thermo Fisher Scientific, Inc.; 1:40 in PBS), anti-mouse Ly-6G conjugated with PE (cat. no. 12-5931-82; Invitrogen; Thermo Fisher Scientific, Inc.; 1:240 in PBS) and anti-CD11b conjugated with allophycocyanin 
(cat. no. 17-0112-82; eBioscience; Thermo Fisher Scientific, Inc.; 1:120 in PBS) or isotype controls were added at $37^{\circ} \mathrm{C}$ for $30 \mathrm{~min}$, in the dark. The cells were centrifuged and re-suspended in $500 \mu \mathrm{l}$ PBS for flow cytometric analysis in the BD FACSCalibur (Becton-Dickinson and Company). All of the FACS data were analyzed with FlowJo v10 (FlowJo LLC).

Fluorescence microscopy. The lung samples from the mice were immobilized with OCT (Sakura Finetek Europe B.V.) at $-80^{\circ} \mathrm{C}$ for $\geq 24 \mathrm{~h}$. The frozen samples were cut on a cryostat microtome, and the $7-\mu \mathrm{m}$ sections were placed on polylysine-coated glass slides. The tissue sections were fixed in $4^{\circ} \mathrm{C}$ acetone and rehydrated in PBS. The slides were gently washed in PBS for three times and then blocked with 5\% goat serum (cat. no. 16210-064; Gibco; Thermo Fisher Scientific, Inc.; 1:500 in PBS) at $37^{\circ} \mathrm{C}$ to reduce non-specific binding. After $30 \mathrm{~min}$, the sections were washed with PBS and stained with Histone H3 (citrulline R2+R8+R17) antibody (cat. no. ab5103; Abcam; 1:300 diluted) (23) overnight at $4^{\circ} \mathrm{C}$ in the dark. Subsequently, the sections were gently washed in PBS and then stained with the fluorescent-conjugated secondary antibody [Goat anti-Rabbit IgG $(\mathrm{H}+\mathrm{L})$ Alexa Fluor ${ }^{\circledR} 555$ conjugate, cat. no. A-21428; Invitrogen; Thermo Fisher Scientific, Inc.] at $37^{\circ} \mathrm{C}$ for $60 \mathrm{~min}$ in the dark. After the unbound fluorescent antibody was removed, the sections were incubated with SYTOX Green diluted in PBS $(1: 2,000)$ at $37^{\circ} \mathrm{C}$ for $15 \mathrm{~min}$. The sections were washed again, and then observed and recorded using confocal microscopy (magnification, x100; CarlZeiss LSM710; Zeiss AG).

Histopathology imaging. The lungs were fixed in $10 \%$ neutral-buffered formalin for $24 \mathrm{~h}$ in room temperature, and then were dehydrated and embedded in paraffin. The fixed embedded tissues were cut into $7-\mu \mathrm{m}$ sections on a Leica RM2165 rotary microtome (Leica Microsystems GmbH) and stained with hematoxylin and eosin for $5 \mathrm{~min}$ at room temperature. The histological analyses were performed by two independent pathologists blinded to the treatment groups.

Clinical samples. A total of $2 \mathrm{ml}$ blood was collected from the antecubital veins of patients with or without lung cancer who had undergone pulmonary surgery under general anesthesia from January to March 2017 in the First Affiliated Hospital of Nanjing Medical University. The inclusion criteria were that patients should not have pulmonary infection. Approximately $0.1 \mathrm{ml}$ sputum was also collected from the patients via endotracheal intubation. The sputum was treated with $1.0 \mathrm{ml} 0.1 \%$ DTT for $15 \mathrm{~min}$ at room temperature, re-suspended and filtrated with a $40-\mu \mathrm{m}$ cell strainer, and centrifuged at $1,000 \mathrm{x}$ g for $5 \mathrm{~min}$ at $4^{\circ} \mathrm{C}$. The supernatant was analyzed for the quantity of NET elastase according to the manufacturer's protocol. Briefly, the lung tissues with or without lung cancer were fixed in OCT (Sakura Finetek Europe B.V.) at $-80^{\circ} \mathrm{C}$ for $\geq 24$ h. Fluorescence microscopy was conducted as described for the mouse samples. All of the human experiments were approved by the Institutional Human Ethics Committee of the First Affiliated Hospital of Nanjing Medical University (Nanjing, China; approval no. 2017-SR-243) with written informed consent from all subjects and it was conducted in accordance with the Declaration of Helsinki ethical guidelines.
NET quantification. NETs were quantified using a NETs assay kit (cat. no. 601010; Cayman Chemical Company) according to the manufacturer's protocol (24). Briefly, the free elastase was washed away followed the generation of NETs induced by LLC cell culture supernatant or activated MLE-12 cells. The samples were further digested with S7 nuclease (10107921001; Sigma-Aldrich; Merck KGaA). The supernatant containing neutrophil elastase was added to the selective substrate and quantified at $405 \mathrm{~nm}$. The concentration of NETs in each sample was calculated according to the NET standards provided by the kit. A total of $1 \mathrm{ml}$ blood sample from mice was collected before mice eutanasia. In the BALF and serum of mice, sputum and serum of patients, free elastase was quantified based on the standard.

Statistical analysis. All statistical analyses were conducted using GraphPad Prism 7 (GraphPad Software, Inc.) and SPSS version 12.0 (SPSS, Inc.). Statistically significant differences were determined using Student's t-test for two groups or analysis of variance for more than two groups, followed by the Dunnett comparison. All data are expressed as the mean \pm standard error of the mean. $\mathrm{P}<0.05$ was considered to indicate a statistically significant difference.

\section{Results}

exRNAs from lung cancer cells activate MLE-12 cells. RNA-selective dye was used to stain intracellular RNAs in the LLC cells. Without FBS and enough glucose, the starving LLC cells underwent nuclear condensation and enhanced distribution of RNAs in the nucleus (Fig. 1A). In the CCS from starving LLC cells, RNase1 digested nucleic acids in the agarose gel, suggesting that RNase1-sensitive exRNAs existed in the CCS from starving LLC cells (Fig. 1B). The CCS from the starving LLC cells increased the levels of the inflammatory cytokine IL-1 $\beta$ in the MLE-12 cells (Fig. 1C). Notably, RNase1 pretreatment abolished the effects of CCS on IL-1 $\beta$ in the MLE-12 cells (Fig. 1D and E). Conversely, the levels of the adhesion molecule VCAM-1 were significantly reduced upon CCS treatment (Fig. 1F). In accordance, RNase1 pretreatment rescued VCAM-1 transcription (Fig. 1G) and protein expression (Fig. 1H and I). In summary, exRNAs from starving lung cancer cells upregulated IL-1 $\beta$ and reduced VCAM-1 in MLE-12 cells, implying that exRNAs from lung cancer cells may activate MLE-12 cells.

Activated MLE-12 cells promote NETs. Neutrophil infiltration occurs frequently in lung cancer (25). To observe whether activated MLE-12 cells can provoke NETs, neutrophils were seeded on a MLE-12 cell monolayer that was treated with or without CCS. As shown in Fig. 2A, the CCS-treated MLE-12 cells induced NETs. RNase1 treatment abolished the formation of NETs, suggesting that exRNAs may be essential in the development of NETs. IL-1 $\beta$ is a potent inducer of NETs (26). In the present study, IL-1 $\beta$ inhibitor blocked the NETs induced by activated MLE-12 cells. In the formation of NETs, DNA from neutrophils is associated with elastase (27). Therefore, NET-specific elastase DNA was quantified in Fig. 2B. Compared to the medium control, the CCS-treated MLE-12 cells had significantly increased 
A

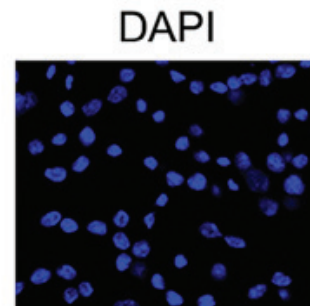

RNA select dye
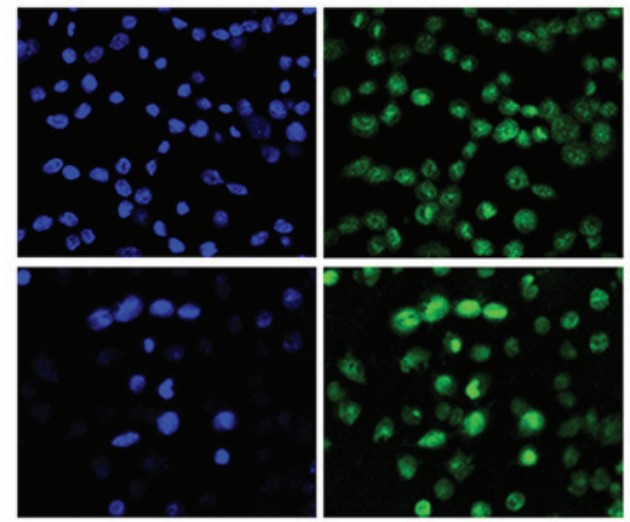

C

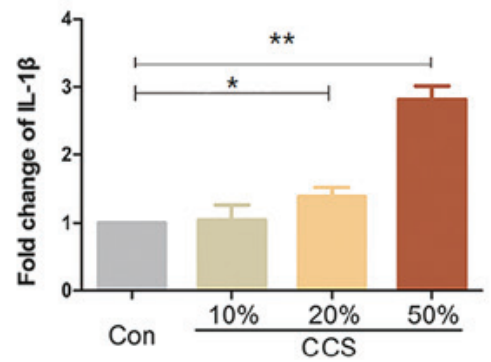

F

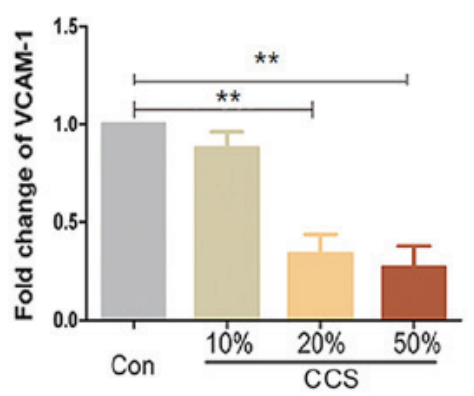

H

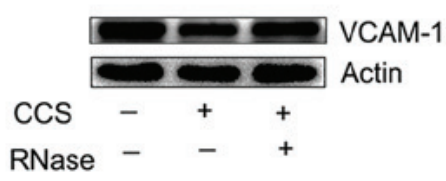

B

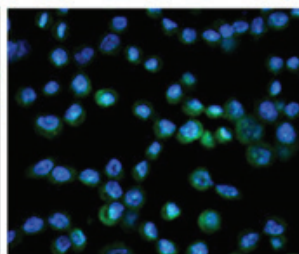

$10 \%$ FBS

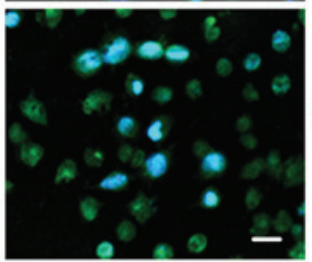

FBS-Free

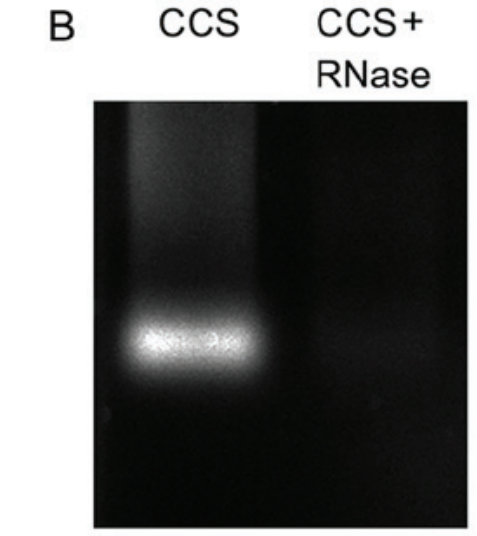

$\mathrm{E}$
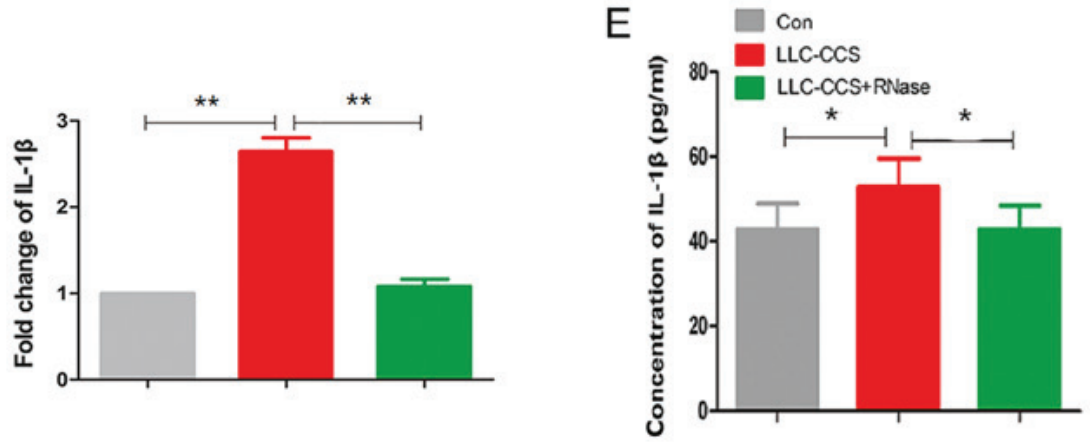

\section{G}

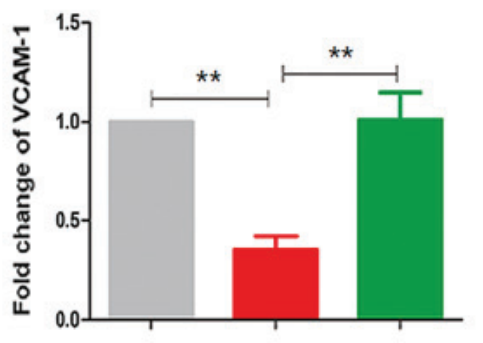

I

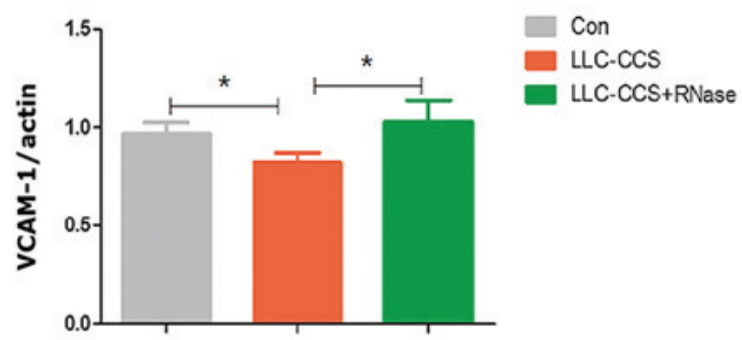

Figure 1. exRNAs from sera-deprived LLC cells activate MLE-12 cells. (A) RNA-selective dye (green) was used to stain the intracellular RNAs in the LLC cells prior to and following starvation. The nuclear DNA was stained with DAPI (blue). Scale bar, $10 \mu \mathrm{m}$. (B) CCS treated with or without RNase1 was processed with RNA agarose gel electrophoresis and the RNasel almost completely digested the CCS nucleic acids. (C) MLE-12 cells were treated with different concentrations of CCS and the levels of IL-1 $\beta$ in the epithelial cells were quantified using a RT-qPCR assay. (D and E) RNase1 reduced the levels of IL-1 $\beta$ transcription and translation in the RT-qPCR assay and in the enzyme-linked immunosorbent assay. The CCS reduced VCAM-1 in the epithelial cells and RNase1 suppressed the effects of CCS in the (F and G) RT-qPCR assay and (H and I) the western blot assay. All experiments were repeated with similar results at least 3 times. exRNA, extracellular RNA; CCS, cell culture supernatant; RT-qPCR, reverse transcription-quantitative PCR; IL, interleukin; VCAM, vascular cell adhesion molecule. ${ }^{*} \mathrm{P}<0.05 ;{ }^{* *} \mathrm{P}<0.01$.

levels of elastase DNA. As expected, RNase1 or IL-1 $\beta$ downregulated the NETs, suggesting that promotion of NETs by CCS-activated MLE-12 cells is at least partially dependent on exRNAs in the CCS and IL-1 $\beta$ released from the MLE-12 cells.
NETs damage MLE-12 cells. Activated MLE-12 cells initiate the formation of NETs and their cross-talk was directly observed in Fig. 3A. The integrity of the epithelium is closely associated with junction proteins. Claudins are considered as gatekeepers of lung epithelial function $(28,29)$. In the 

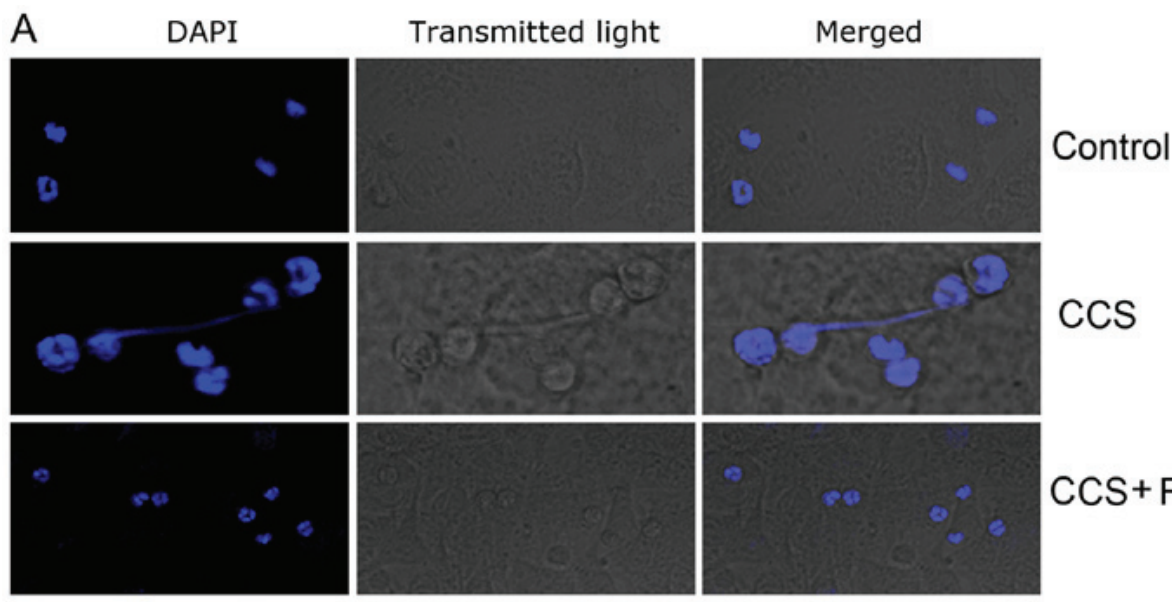

CCS
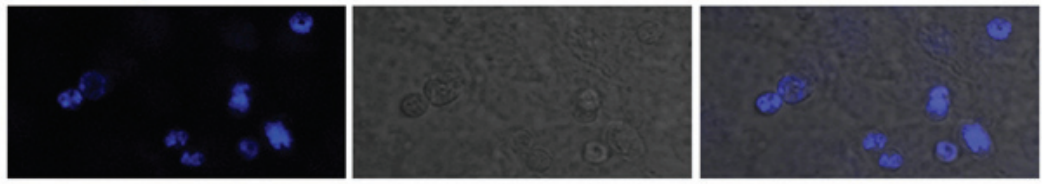

CCS+ IL-1 $\beta$ inhibitor

B
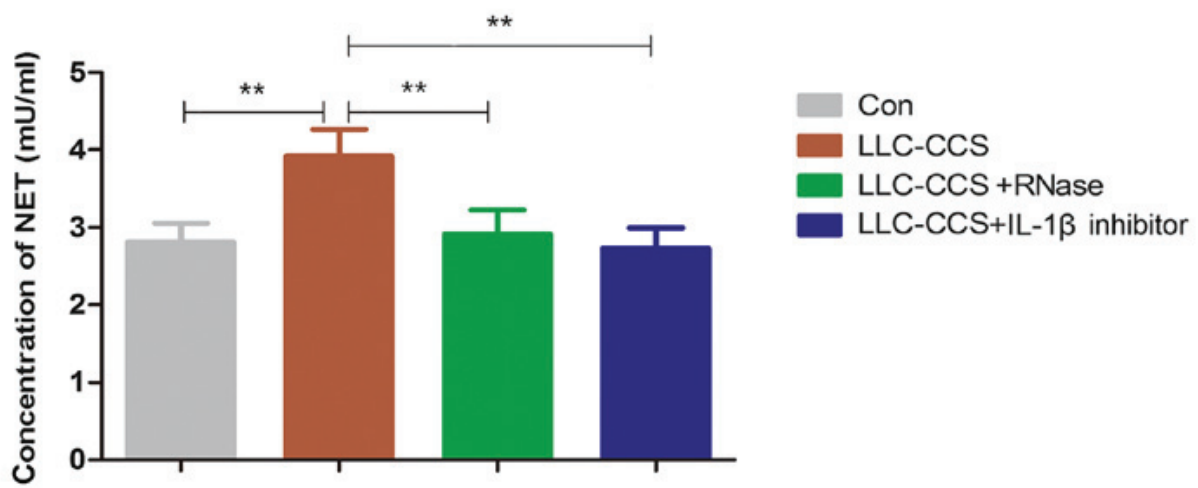

Figure 2. exRNA-activated MLE-12 cells promote NETs. (A) Immunofluorescence staining revealed that the CCS produced NETs, while RNase1 and IL-1 $\beta$ inhibitor aborted the formation of NETs. (B) The NETs in each group were quantified in the NET assay. All experiments were repeated with similar results at least 3 times. exRNA, extracellular RNA; NET, neutrophil extracellular traps; CCS, cell culture supernatant; IL, interleukin. ${ }^{*} \mathrm{P}<0.05$; ${ }^{* *} \mathrm{P}<0.01$.

present study, the levels of tight junction claudin-5 in the MLE-12 cells were significantly reduced upon treatment with NETs (Fig. 3B and C), suggesting that NETs may damage MLE-12 cells. Furthermore, the NETs promoted the death of MLE-12 cells, as indicated by the PI-positive cells (Fig. 3D). The master regulatory factor caspase-3 was significantly activated upon treatment with the NETs (Fig. 3E and F). Therefore, the death of MLE-12 cells may be mediated by caspase- 3 activation. As the dead LLC cells produced exRNAs, the death of the MLE-12 cells also released exRNAs into the supernatant (Fig. 3G). Collectively, NETs damage MLE-12 cells and promote the secretion of exRNAs.

Self-activation of MLE-12 cells via exRNAs. To address whether exRNAs from dead MLE-12 cells can activate healthy MLE-12 cells, MLE-12 cells were stimulated with CCS from dead lung cancer cells or MLE-12 cells. With the increased concentration of CCS in the culture medium, the levels of the pro-inflammatory cytokine IL-1 $\beta$ were progressively increased (Fig. 4A). RNase1 significantly reduced the transcription and translation of IL- $\beta$ in the MLE-12 cells treated with CCS from the epithelial cells (Fig. 4B and C). As observed in the LLC cell CCS, the MLE-12 cell CCS downregulated the cell adhesion molecule VCAM-1 at mRNA and protein expression levels, which was partially attenuated by RNase1 (Fig. 4D-G). Therefore, exRNAs from MLE-12 cells activate epithelial cells.

Lung cancer cells recruit and activate neutrophils in vivo. In the murine model of lung cancer, LLC cells were intratracheally instilled into the lung. As shown in Fig. 5A, the instillation of the LLC cells significantly exacerbated the inflammation in the lung. Neutrophils, which were CD $45^{+} \mathrm{CD} 11 \mathrm{~b}^{+} \mathrm{Ly}_{6 \mathrm{G}^{+}}$, were recruited into the lung parenchyma (Fig. 5B). Notably, CD11b expression on the neutrophils was significantly enhanced in the mice that received LLC cells (Fig. 5C), suggesting that LLC cells activate neutrophils in vivo. In line with this observation, the levels of neutrophils in the BALF were also significantly increased (Fig. 5D). The levels of elastase were significantly augmented in the BALF (Fig. 5E) and sera (Fig. 5F) from the LLC-treated mice, suggesting that the lung cancer cells induced neutrophil activation and potential NET formation in vivo.

NETs in patients with lung cancer. The aforementioned results demonstrated that exRNAs from lung cancer cells provoke NETs in vitro and in the mice. In the clinical 
A

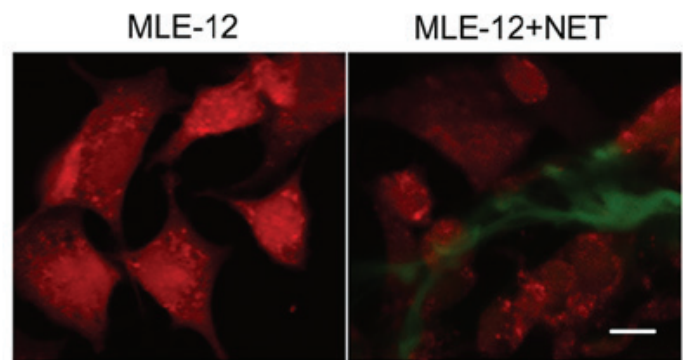

C

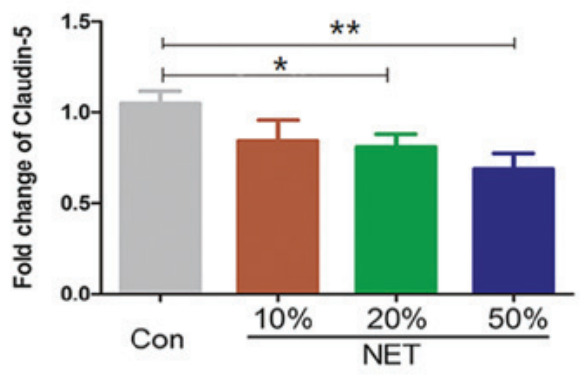

B

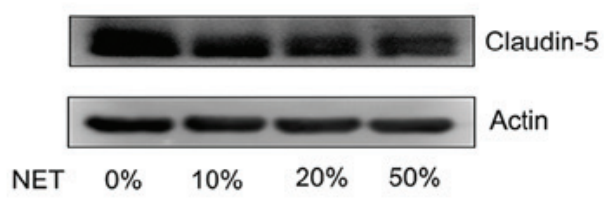

D

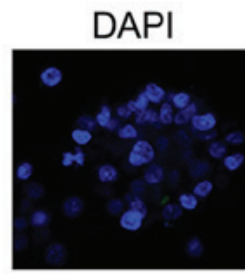

PI

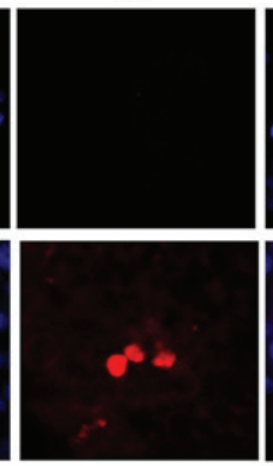

Merged
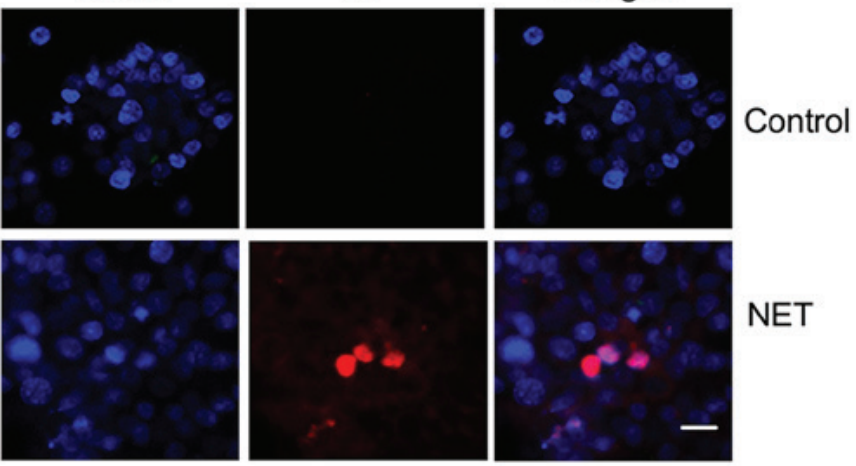

F

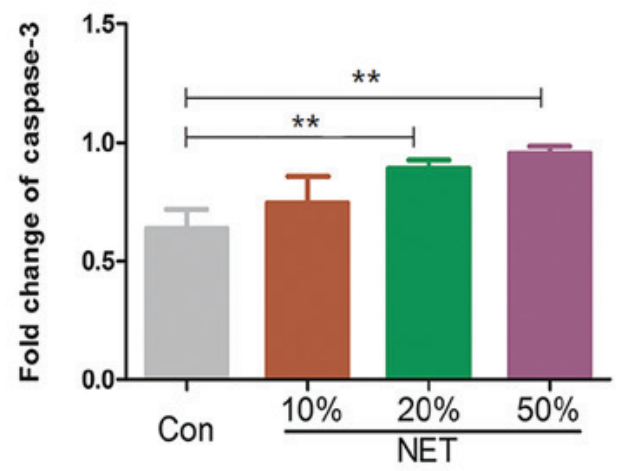

$32 \mathrm{kDa}$
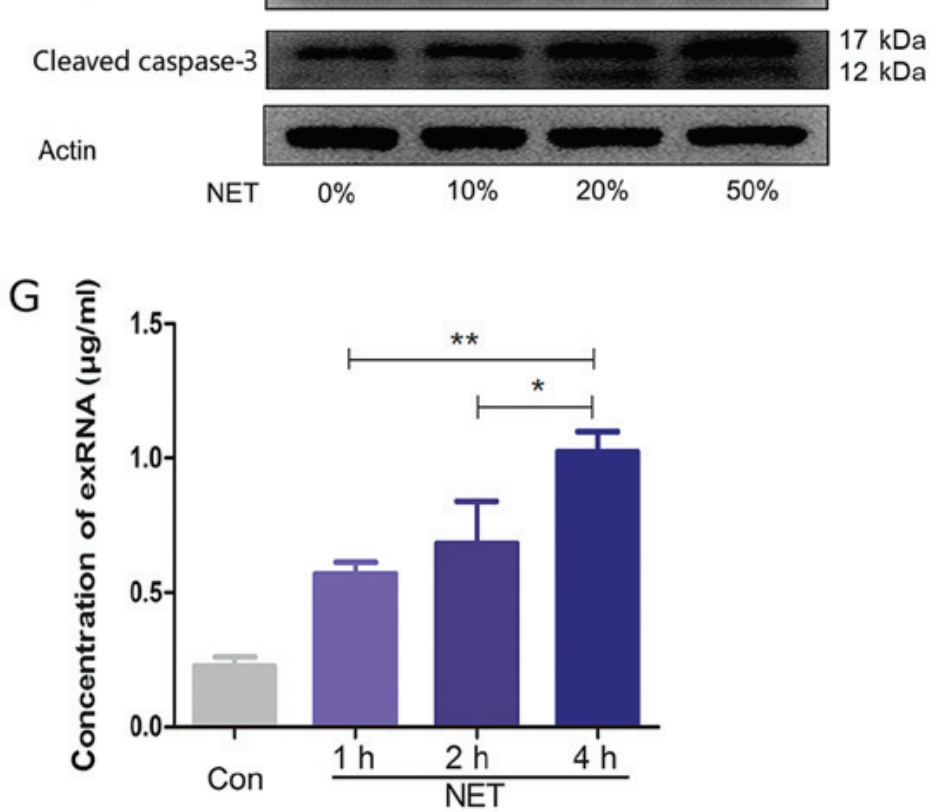

Figure 3. NETs damage MLE-12 cells. (A) Direct contact between NETs (green) and MLE-12 cells (red). Scale bar, $10 \mu \mathrm{m}$. (B and C) The expression of claudin-5 in the MLE-12 cells was downregulated by the NETs. (D) The NETs caused the necrosis of the MLE-12 cells. The necrotic cells were stained with propidium iodide (red) and the nucleus was stained with DAPI (blue). Scale bar, $20 \mu \mathrm{m}$. (E and F) The western blotting demonstrates that the NETs increased the activation of caspase 3. (G) exRNAs in the supernatant of the NET-treated MLE-12 cells were quantified using the Quant-iT ${ }^{\mathrm{TM}}$ RiboGreen $^{\mathrm{TM}}$ RNA Assay Kit. All experiments were repeated at least 3 times. NET, neutrophil extracellular traps; exRNA, extracellular RNA. " $\mathrm{P}<0.05 ;{ }^{*} \mathrm{P}<0.01$.

samples, the formation of NETs was observed in the lung tissues from the patients with lung cancer but not in those from the patients with pulmonary bulla (Fig. 6A). In line with the immunofluorescence observation, the levels of the NET hallmark elastase were significantly increased in either the sputum or the peripheral blood (Fig. 6B and C), suggesting that lung cancer may be accompanied with NETs.

\section{Discussion}

The present study showed that the exRNAs released from lung cancer cells indirectly promoted the formation of NETs via activating epithelial cells. Administration of RNase1 significantly blocked the roles of exRNAs in the NETs induction and epithelial cells activation. Outside of the cell, 
A

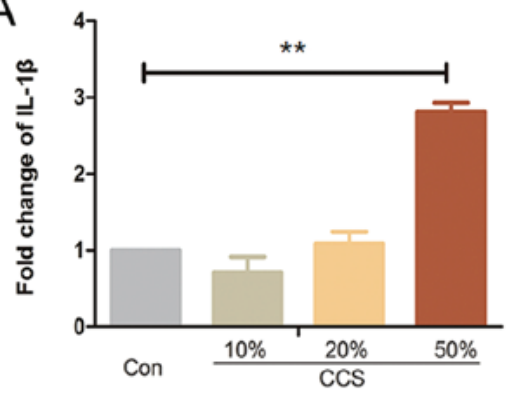

D

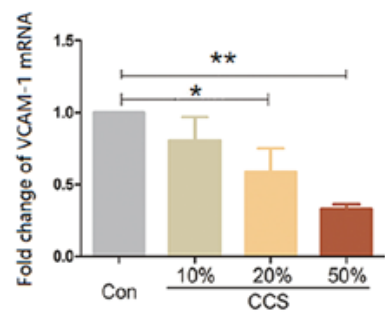

E

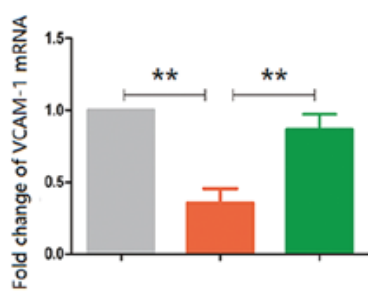

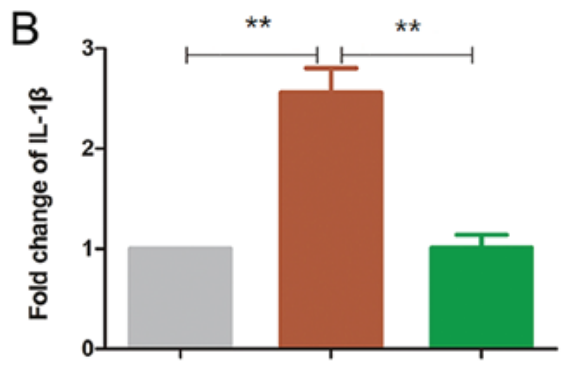

$\mathrm{F}$

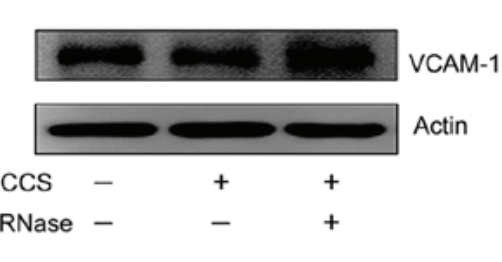

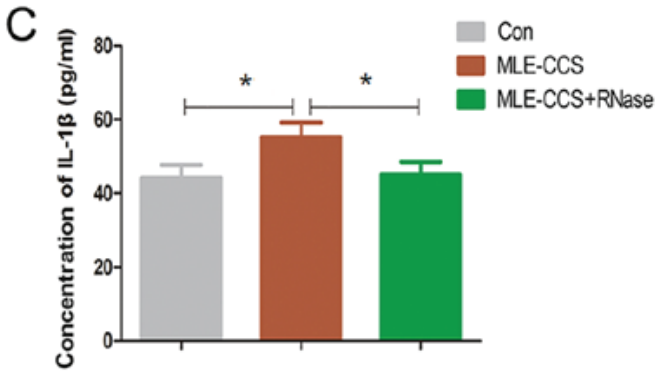

G

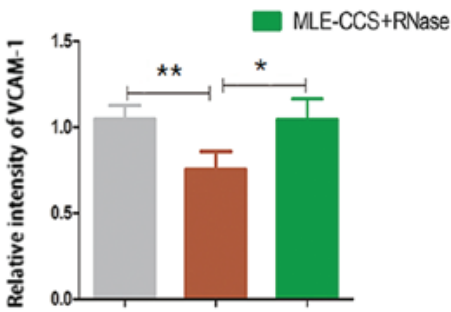

Figure 4. CCS from MLE-12 cells activates epithelial cells. (A-C) The CCS increased the levels of IL-1 $\beta$ in the epithelial cells, which was suppressed by RNase1. (D-G) The CCS reduced the levels of VCAM-1 in the epithelial cells and RNase1 increased them on the epithelial cells treated with CCS from MLE-12 cells. All experiments were repeated at least 3 times. CCS, cell culture supernatant. IL, interleukin; VCAM, vascular cell adhesion molecule. ${ }^{*} \mathrm{P}<0.05$; ${ }^{* *} \mathrm{P}<0.01$.

miRNAs containing $\sim 22$ nucleotides are stable. In contrast to miRNAs, mRNAs and long non-coding RNAs (lncRNAs) in the extracellular medium are relatively sensitive to RNase1 (30). Similarly, it was postulated that lung cancer cells may release RNase1-sensitive mRNAs and/or lncRNAs into the extracellular space.

Lung cancer cells exRNAs evoke the secretion of IL-1 $\beta$ from bronchia epithelial cells. Epithelial cells express Toll like receptor3, Retinoic acid-inducible gene-1 and Melanoma differentiation-associated protein-5, which may be responsible for exRNA recognition and activation of the signaling pathway to epithelial cells (31). VCAM-1 is an inducible adhesion molecule expressed by respiratory endothelial and epithelial cells (32). In endothelial cells, IL-1 $\beta$ increases the levels of VCAM-1 expression $(33,34)$. However, in respiratory epithelial cells, VCAM-1 expression is not affected by IL-1 $\beta$ (32). Instead, exRNAs in the lung cancer cell CCS upregulate IL-1 $\beta$ and reduce VCAM-1 expression on epithelial cells. VCAM-1 may mediate the leukocyte infiltration across respiratory epithelial cells (32). As an adhesion molecule, VCAM-1 is bound with integrin $\alpha 4 \beta 1$ mediating leukocyte transmigration. The tight junction protein JAM may also interact with integrin $\alpha 4 \beta 1$ (35), indicating that VCAM-1 contributes to epithelial integrity. Soluble VCAM-1 impairs the integrity of the blood-brain barrier (BBB) via $\alpha 4 \beta 1$ (36). In the present study, intratracheal instillation of LLC cells recruited neutrophils into the lung parenchyma and BALF, suggesting that leukocyte infiltration was enhanced. Due to lack of special marker for LLC, lung cancer cells were not directly detected in the pulmonary parenchyma. Collectively, it was postulated that CCS exRNAs damage epithelial cells, resulting in reduced integrity and increased leukocyte infiltration, but this needs to be verified.

It was previously reported that activated endothelial cells induce NETs, which is partially dependent on IL-8 (37). IL-1 $\beta$ is also a potential inducer of NETs (26). In the present study, exRNA-treated MLE-12 cells promoted the formation of NETs, which was closely associated with exRNAs and IL-1 $\beta$. NETs not only kill pathogens but can also cause tissue injury (27). As NETs damage endothelial cells (38), in the present study NETs directly reduced the expression of claudin-5 in the epithelial cells. In claudin-5-deficient mice, BBB integrity against small molecules is severely compromised (39). In respiratory epithelial cells, increased claudin-5 expression reduces alveolar epithelial barrier function (29). Therefore, the downregulation of claudin-5 in the MLE-12 cells by NETs in the present study is arguable and requires further research. In the present study, NETs induced the death of MLE-12 cells, which may be associated with caspase-3. Furthermore, NETs triggered the secretion of exRNAs from the starving MLE-12 cells. As observed in the lung cancer cell exRNAs, the MLE-12 cell exRNAs also affected IL-1 $\beta$ and VCAM-1 in epithelial cells. Thus, there may be positive feedback in the reaction cascade as follows: i) exRNAs from damaged lung tumor cells activate epithelial cells; ii) activated epithelial cells promote NETs; ii) NETs cause the secretion of exRNAs from necrotic epithelial cells; and iv) exRNAs from the necrotic epithelial cells activate the neighboring healthy epithelial cells. As we demonstrated that poly I:C induced NETs in the lung (21) and other organs $(40,41)$, the double RNA analogy poly I:C could directly induce the formation of NETs in vitro (data unpublished). Indeed, poly I:C induced NETs were used in this study to explore the interactions between NETs and epithelial cells. Therefore, we could not preclude the possibility that exRNAs from cancer cells may directly trigger NETs formation.

It has been widely recognized that NETs facilitate tumor progression and metastasis (42). In the present study, NETs were recorded in the patients with lung cancer, not only in the lung tissues but also in the peripheral blood and sputum. The 
A

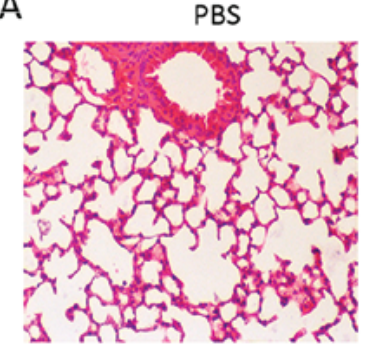

LLC

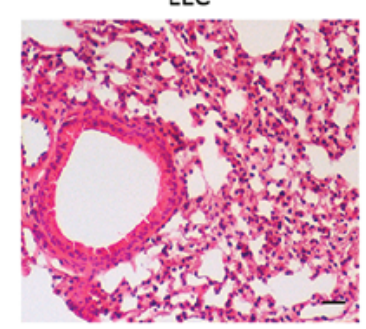

B

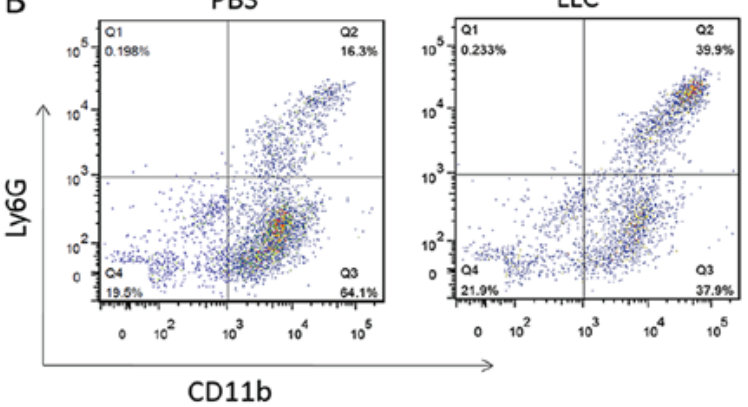

C

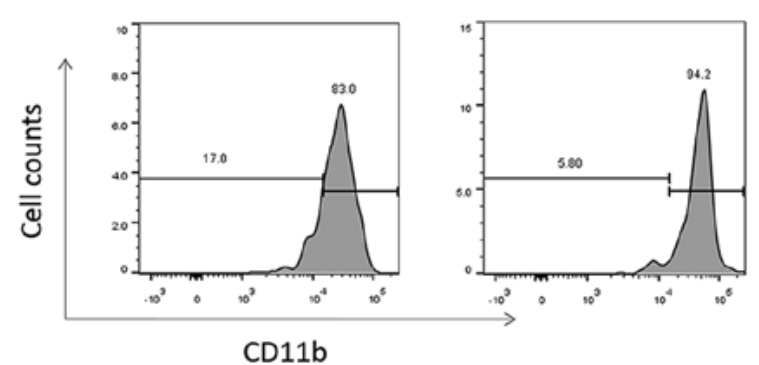

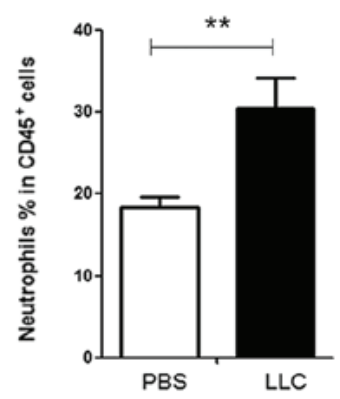

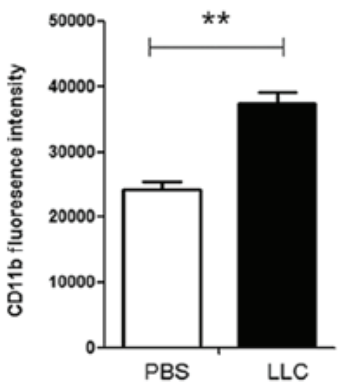

D
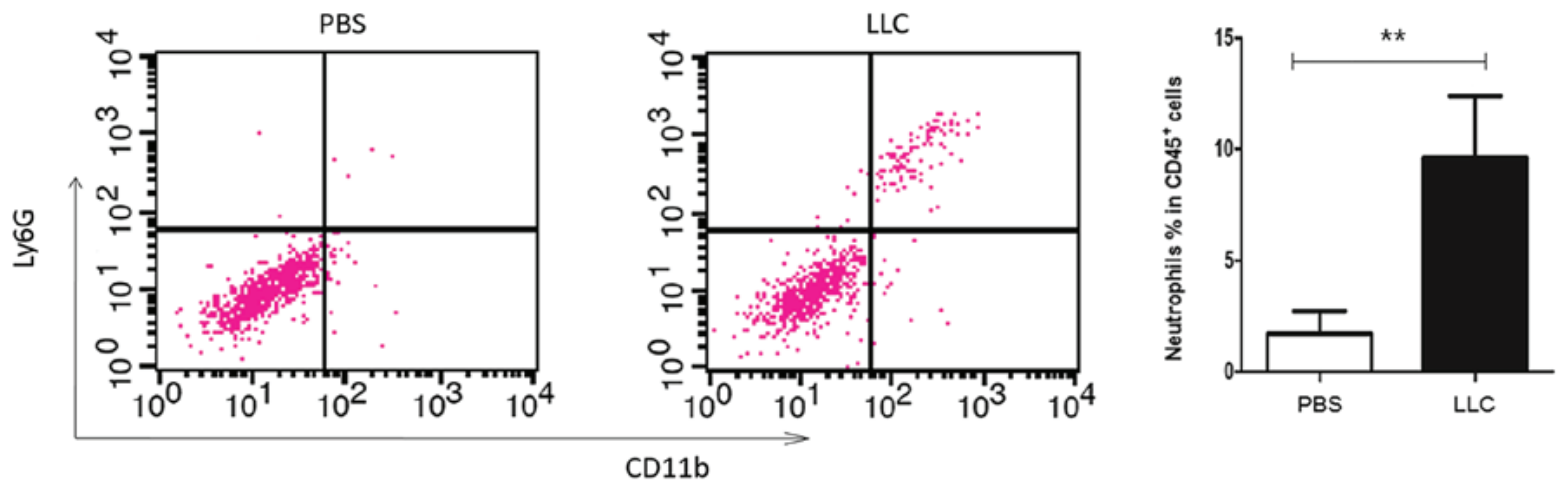

E

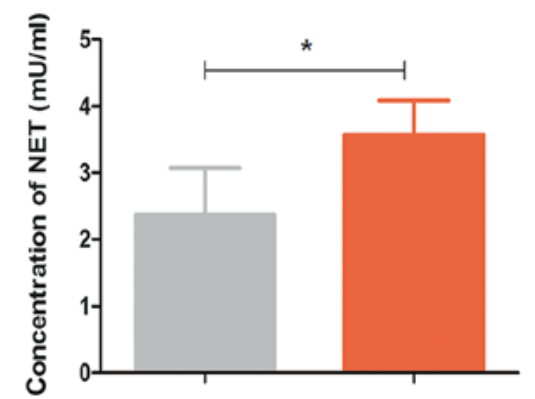

F

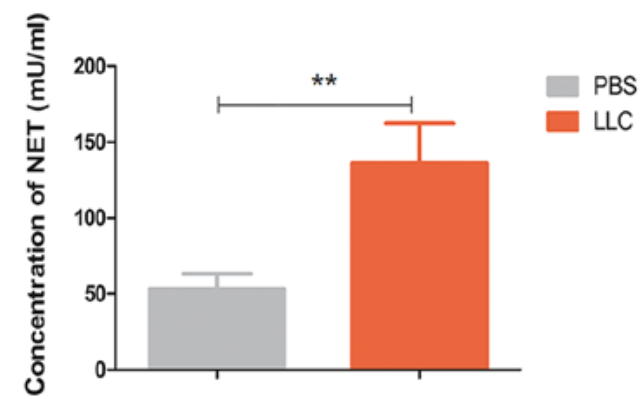

Figure 5. Lung cancer cells recruit neutrophils and produce NETs in vivo. (A) Lung tissues from the mice instilled with LLC cells were stained with hematoxylin and eosin. Scale bar, $20 \mu \mathrm{m}$. (B) The flow cytometry assay revealed enhanced infiltration of neutrophils into the lung tissues. The CD11 ${ }^{+} \mathrm{Ly}^{6} \mathrm{G}^{+}$ cells were gated from the $\mathrm{CD} 45^{+}$cells. (C) The mean fluorescence intensity of CD11b was significantly increased in the cells from the mice instilled with LLC cells. (D) In the BALF, the levels of neutrophil infiltration were significantly increased in the LLC cell-treated mice. The concentration of NETs in the (E) BALF and (F) sera was quantified. All experiments were repeated at least 3 times. NET, neutrophil extracellular traps; CD, cluster of differentiation; BALF, bronchoalveolar lavage fluid. ${ }^{*} \mathrm{P}<0.05 ;{ }^{* *} \mathrm{P}<0.01$.

danger-associated molecular pattern protein high mobility group box 1 (HMGB1) can induce NET formation (43). HMGB1 serves essential roles in lung cancer tumorigenesis and metastasis (44). In the consideration that cell culture supernatant may contain exosomes, cytokines and other biological components, the possibility that all of these factors, including exRNAs and HMGB1, may be jointly involved with NETs formation and tumor progression, cannot be excluded.
In summary, the results of the present study demonstrated that activated epithelial cells induce NETs via exRNAs from lung cancer cells (Fig. 7), adding the recognition of novel roles of exRNAs for cancer development (42). RNasel and IL-1 $\beta$ inhibitor may be potential tools to block the formation of NETs induced by exRNAs and activated epithelial cells. Further studies on the cross-talk between exRNAs and NETs in lung cancer and other types of cancer are required. 
A
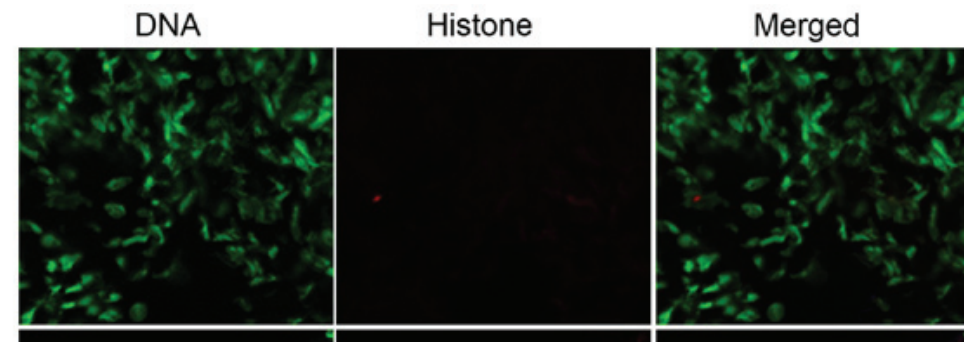

Pulmonary bulla
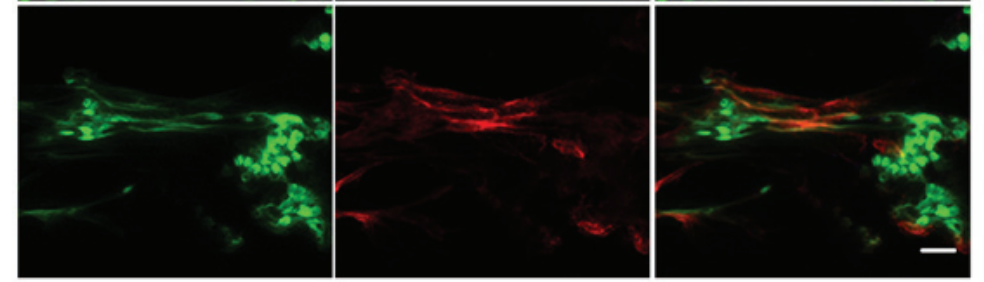

Lung cancer
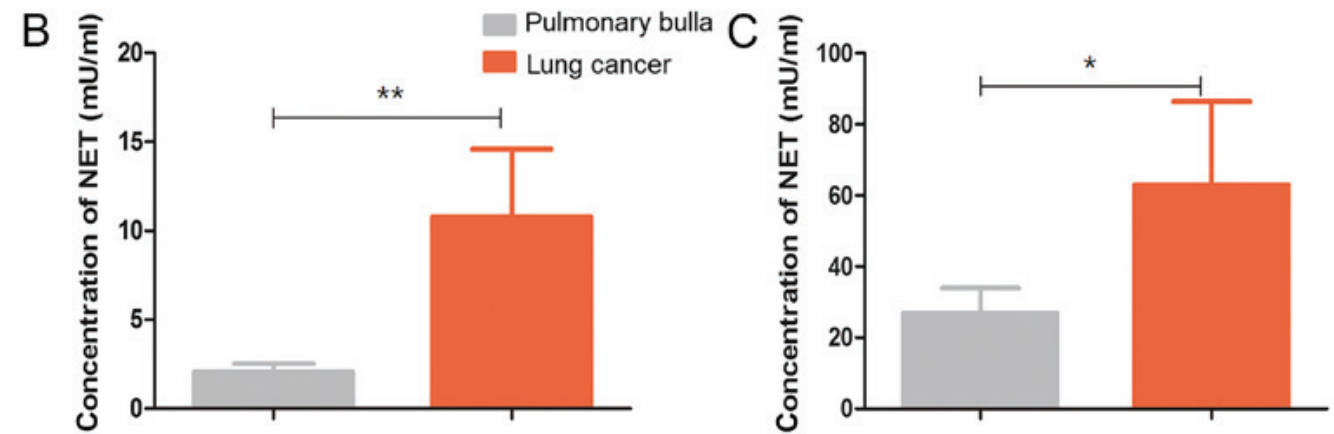

Figure 6. NET formation in patients with lung cancer. (A) The lung tissues from the patients were embedded in OCT, cut, fixed, and stained with SYTOX Green (DNA; green) and anti-histone 3 (red). The lung parenchyma from the patients with lung cancer but not those with pulmonary bulla exhibited NET formation. Scale bar, $10 \mu \mathrm{m}$. The NETs in the (B) sputum and (C) sera from the patients with lung cancer were significantly increased. All experiments were repeated at least 3 times. NET, neutrophil extracellular traps. ${ }^{*} \mathrm{P}<0.05 ;{ }^{* *} \mathrm{P}<0.01$.

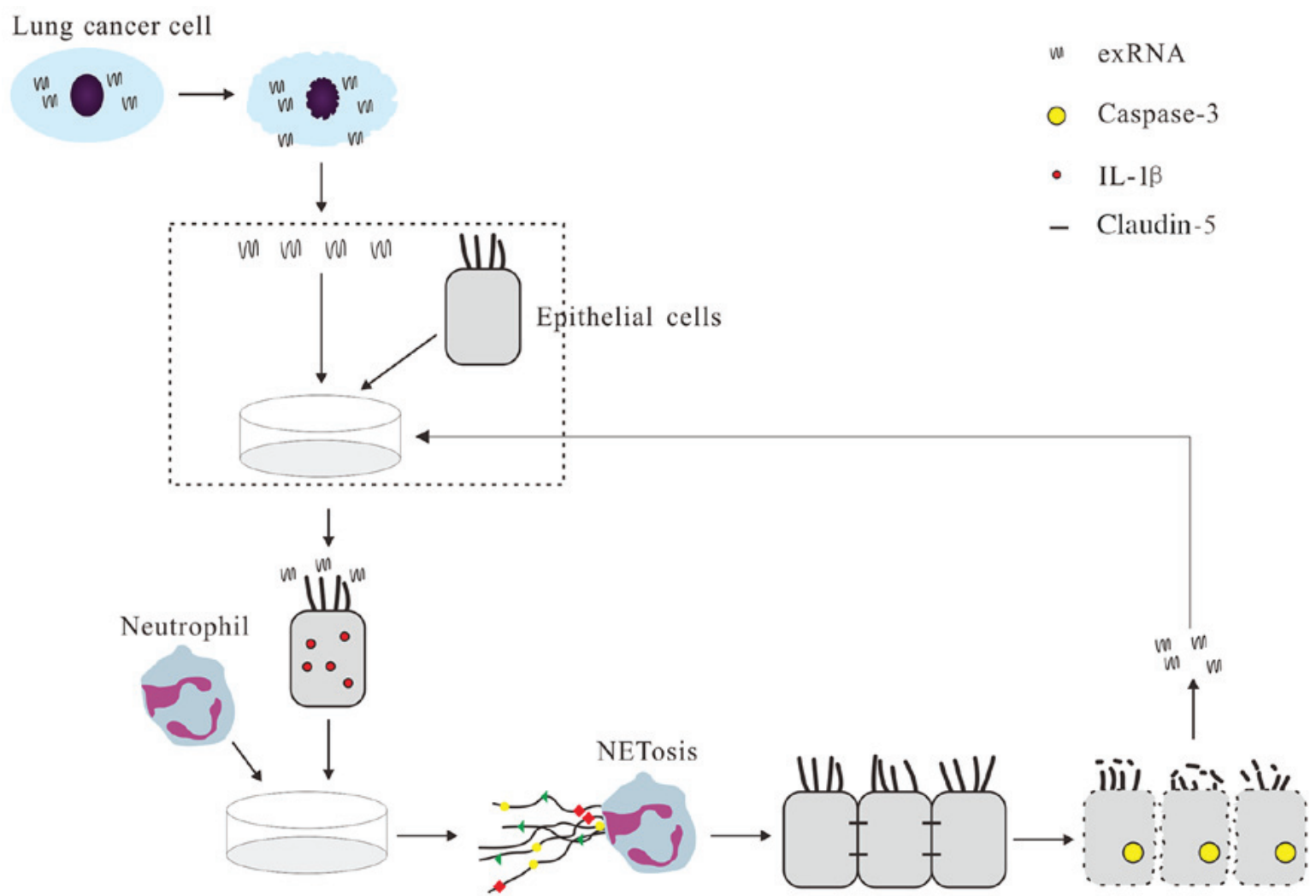

Figure 7. Proposed mechanism of exRNAs from tumor cells on the NETs induction. exRNAs from starving cancer cells promoted IL-1 $\beta$ secretion from epithelial cells. IL-1 $\beta$ stimulated the formation of NETs. NETs damaged epithelial cells and exRNAs released from necrotic epithelial cells again initiated cascade reactions. exRNA, extracellular RNA; IL, interleukin; NET, neutrophil extracellular traps. 


\section{Acknowledgements}

The present study was supported by National Natural Science Foundation of China (grant no. 81671563), Natural Science Foundation of Jiangsu Province (grantno.BK2015155) and Nanjing Medical University key project (grant no. 2014NJMUZD010).

\section{Funding}

The present study was supported by National Natural Science Foundation of China (grant no. 81671563).

\section{Availability of data and materials}

The analyzed data sets generated during the study are available from the corresponding author on reasonable request.

\section{Authors' contributions}

YC and MZ conceived and designed the study. YL, YY, TG and JZ conducted the experiments. FH, NH, BY, and MZ analyzed the results. MZ wrote the paper. All the authors reviewed and approved the manuscript.

\section{Clinics approval and consent to participate}

The present study was carried out in accordance with the recommendations of 'IACUC of Nanjing Medical University' with written informed consent from all subjects. All subjects gave written informed consent in accordance with the Declaration of Helsinki. The protocol was approved by the 'IACUC of Nanjing Medical University'.

\section{Patient consent for publication}

Not applicable.

\section{Competing interests}

The authors declare that they have no competing interests.

\section{References}

1. Hirsch FR, Scagliotti GV, Mulshine JL, Kwon R, Curran WJ Jr, Wu YL and Paz-Ares L: Lung cancer: Current therapies and new targeted treatments. Lancet 389: 299-311, 2017.

2. Wright HL, Moots RJ, Bucknall RC and Edwards SW: Neutrophil function in inflammation and inflammatory diseases. Rheumatology (Oxford) 49: 1618-1631, 2010.

3. Brinkmann V, Reichard U, Goosmann C, Fauler B, Uhlemann Y, Weiss DS, Weinrauch Y and Zychlinsky A: Neutrophil extracellular traps kill bacteria. Science 303: 1532-1535, 2004.

4. Erpenbeck L and Schön MP: Neutrophil extracellular traps: Protagonists of cancer progression? Oncogene 36: 2483-2490, 2017.

5. Barnado A, Crofford LJ and Oates JC: At the Bedside: Neutrophil extracellular traps (NETs) as targets for biomarkers and therapies in autoimmune diseases. J Leukoc Biol 99: 265-278, 2016.

6. Döring Y, Soehnlein O and Weber C: Neutrophil extracellular traps in atherosclerosis and atherothrombosis. Circ Res 120 736-743, 2017.

7. Bar-Ad V, Palmer J, Li L, Lai Y, Lu B, Myers RE, Ye Z, Axelrod R, Johnson JM, Werner-Wasik M, et al: Neutrophil to lymphocyte ratio associated with prognosis of lung cancer. Clin Transl Oncol 19: 711-717, 2017.
8. Cools-Lartigue J, Spicer J, McDonald B, Gowing S, Chow S, Giannias B, Bourdeau F, Kubes P and Ferri L: Neutrophil extracellular traps sequester circulating tumor cells and promote metastasis. J Clin Invest 123: 67484, 2013.

9. Akinosoglou KS, Karkoulias K and Marangos M: Infectious complications in patients with lung cancer. Eur Rev Med Pharmacol Sci 17: 8-18, 2013.

10. Patton JG, Franklin JL, Weaver AM, Vickers K, Zhang B, Coffey RJ, Ansel KM, Blelloch R, Goga A, Huang B, et al: Biogenesis, delivery, and function of extracellular RNA. J Extracell Vesicles 4: 27494, 2015.

11. Kolodny GM: Evidence for transfer of macromolecular RNA between mammalian cells in culture. Exp Cell Res 65: 313-324, 1971.

12. Kolodny GM: Cell to cell transfer of RNA into transformed cells. J Cell Physiol 79: 147-150, 1972.

13. Fischer S, Gesierich S, Griemert B, Schänzer A, Acker T, Augustin HG, Olsson AK and Preissner KT: Extracellular RNA liberates tumor necrosis factor- $\alpha$ to promote tumor cell trafficking and progression. Cancer Res 73: 5080-5089, 2013.

14. Rabinowits G, Gerçel-Taylor C, Day JM, Taylor DD and Kloecker GH: Exosomal microRNA: A diagnostic marker for lung cancer. Clin Lung Cancer 10: 42-46, 2009.

15. Munagala R, Aqil F and Gupta RC: Exosomal miRNAs as biomarkers of recurrent lung cancer. Tumour Biol 37: 10703-10714, 2016.

16. Zhou Q, Huang SX, Zhang F, Li SJ, Liu C, Xi YY, Wang L, Wang X, He QQ, Sun CC, et al: MicroRNAs: A novel potential biomarker for diagnosis and therapy in patients with non-small cell lung cancer. Cell Prolif 50: e12394, 2017.

17. Liu Q, Yu Z, Yuan S, Xie W, Li C, Hu Z, Xiang Y, Wu N, Wu L, Bai L, et al: Circulating exosomal microRNAs as prognostic biomarkers for non-small-cell lung cancer. Oncotarget 8: 13048-13058, 2017.

18. Ni H, Capodici J, Cannon G, Communi D, Boeynaems JM, Karikó K and Weissman D: Extracellular mRNA induces dendritic cell activation by stimulating tumor necrosis factor-alpha secretion and signaling through a nucleotide receptor. J Biol Chem 277: 12689-12696, 2002.

19. Cabrera-Fuentes HA, Ruiz-Meana M, Simsekyilmaz S, Kostin S, Inserte J, Saffarzadeh M, Galuska SP, Vijayan V, Barba I, Barreto G, et al: RNase1 prevents the damaging interplay between extracellular RNA and tumour necrosis factor- $\alpha$ in cardiac ischaemia/reperfusion injury. Thromb Haemost 112: 1110-1119, 2014.

20. Laurent LC, Alexander RP: Cell Culture Supernatant Collection. In: PROTOCOL (Version 1). Protocol Exchange, 2015. https:// doi.org/10.1038/protex.2015.107. Accessed December 21, 2015.

21. Gan T, Yang Y, Hu F, Chen X, Zhou J, Li Y, Xu Y, Wang H, Chen Y and Zhang M: TLR3 regulated poly I:C-induced neutrophil extracellular traps and acute lung injury partly through p38 MAP kinase. Front Microbiol 9: 3174, 2018.

22. Livak KJ and Schmittgen TD: Analysis of relative gene expression data using real-time quantitative PCR and the 2(-Delta Delta C(T)) method. Methods 25: 402-408, 2001.

23. Hirose T, Hamaguchi S, Matsumoto N, Irisawa T, Seki M, Tasaki O, Hosotsubo H, Yamamoto N, Yamamoto K, Akeda Y, et al: Presence of neutrophil extracellular traps and citrullinated histone $\mathrm{H} 3$ in the bloodstream of critically ill patients. PLoS One 9: e111755, 2014.

24. Yizengaw E, Getahun M, Tajebe F, Cruz Cervera E, Adem E, Mesfin G, Hailu A, Van der Auwera G, Yardley V,Lemma M, et al: Visceral leishmaniasis patients display altered composition and maturity of neutrophils as well as impaired neutrophil effector functions. Front Immunol 7: 517, 2016.

25. Stankovic B, Bjørhovde HAK, Skarshaug R, Aamodt H, Frafjord A, Müller E, Hammarström C, Beraki K, Bækkevold ES, Woldbæk PR, et al: Immune cell composition in human non-small cell lung cancer. Front Immunol 9: 3101, 2019.

26. Keshari RS, Jyoti A, Dubey M, Kothari N, Kohli M, Bogra J, Barthwal MK and Dikshit M: Cytokines induced neutrophil extracellular traps formation: Implication for the inflammatory disease condition. PLoS One 7: e48111, 2012.

27. Kaplan MJ and Radic M: Neutrophil extracellular traps: Double-edged swords of innate immunity. J Immunol 189: 2689-2695, 2012.

28. Soini Y: Claudins in lung diseases. Respir Res 12: 70, 2011.

29. Schlingmann B, Molina SA and Koval M: Claudins: Gatekeepers of lung epithelial function. Semin Cell Dev Biol 42: 47-57, 2015.

30. Tsui NB, Ng EK and Lo YM: Stability of endogenous and added RNA in blood specimens, serum, and plasma. Clin Chem 48: 1647-1653, 2002 . 
31. Slater L, Bartlett NW, Haas JJ, Zhu J, Message SD, Walton RP, Sykes A, Dahdaleh S, Clarke DL, Belvisi MG, et al: Co-ordinated role of TLR3, RIG-I and MDA5 in the innate response to rhinovirus in bronchial epithelium. PLoS Pathog 6: e1001178, 2010.

32. Papi A and Johnston SL: Respiratory epithelial cell expression of vascular cell adhesion molecule-1 and its up-regulation by rhinovirus infection via NF-kappaB and GATA transcription factors. J Biol Chem 274: 30041-30051, 1999.

33. Marui N, Offermann MK, Swerlick R, Kunsch C, Rosen CA, Ahmad M, Alexander RW and Medford RM: Vascular cell adhesion molecule-1 (VCAM-1) gene transcription and expression are regulated through an antioxidant-sensitive mechanism in human vascular endothelial cells. J Clin Invest 92 1866-1874, 1993

34. Skerrett SJ, Liggitt HD, Hajjar AM, Ernst RK, Miller SI and Wilson CB: Respiratory epithelial cells regulate lung inflammation in response to inhaled endotoxin. Am J Physiol Lung Cel Mol Physiol 287: L143-L152, 2004.

35. Ebnet K, Suzuki A, Ohno S and Vestweber D: Junctional adhesion molecules (JAMs): More molecules with dual functions? J Cell Sci 117: 19-29, 2004.

36. Haarmann A, Nowak E, Deiss A, van der Pol S, Monoranu CM, Kooij G, Müller N, van der Valk P, Stoll G, de Vries HE, et al: Soluble VCAM-1 impairs human brain endothelial barrier integrity via integrin $\alpha$-4-transduced outside-in signalling. Acta Neuropathol 129: 639-652, 2015.

37. Gupta AK, Joshi MB, Philippova M, Erne P, Hasler P, Hahn S and Resink TJ: Activated endothelial cells induce neutrophil extracellular traps and are susceptible to NETosis-mediated cell death. FEBS Lett 584: 3193-3197, 2010.

38. Villanueva E, Yalavarthi S, Berthier CC, Hodgin JB, Khandpur R, Lin AM, Rubin CJ, Zhao W, Olsen SH, Klinker M, et al: Netting neutrophils induce endothelial damage, infiltrate tissues, and expose immunostimulatory molecules in systemic lupus erythematosus. J Immunol 187: 538-552, 2011.
39. Nitta T, Hata M, Gotoh S, Seo Y, Sasaki H, Hashimoto N, Furuse $M$ and Tsukita S: Size-selective loosening of the blood-brain barrier in claudin-5-deficient mice. J Cell Biol 161: 653-660, 2003.

40. Jenne CN, Wong CH, Zemp FJ, McDonald B, Rahman MM Forsyth PA, McFadden G and Kubes P: Neutrophils recruited to sites of infection protect from virus challenge by releasing neutrophil extracellular traps. Cell Host Microbe 13: 169-180, 2013.

41. Arai Y,YamashitaK,KuriyamaK,ShiokawaM,KodamaY,SakuraiT, Mizugishi K, Uchida K, Kadowaki N, Takaori-Kondo A, et al: Plasmacytoid dendritic cell activation and IFN- $\alpha$ production are prominent features of murine autoimmune pancreatitis and human IgG4-related autoimmune pancreatitis. J Immunol 195: 3033-3044, 2015.

42. Redzic JS, Balaj L, van der Vos KE and Breakefield XO: Extracellular RNA mediates and marks cancer progression. Semin Cancer Biol 28: 14-23, 2014.

43. Tadie JM, Bae HB, Jiang S, Park DW, Bell CP, Yang H, Pittet JF, Tracey K, Thannickal VJ, Abraham E, et al: HMGB1 promotes neutrophil extracellular trap formation through interactions with Toll-like receptor 4. Am J Physiol Lung Cell Mol Physiol 304: L342-L349, 2013.

44. Zhu J, Luo J, Li Y, Jia M, Wang Y, Huang Y and Ke S: HMGB1 induces human non-small cell lung cancer cell motility by activating integrin $\alpha v \beta 3 / \mathrm{FAK}$ through TLR4/NF- $\kappa \mathrm{B}$ signaling pathway. Biochem Biophys Res Commun 480: 522-527, 2016.

(†) $\Theta$ This work is licensed under a Creative Commons Attribution-NonCommercial-NoDerivatives 4.0 International (CC BY-NC-ND 4.0) License. 